\title{
Gramsci y la sociología del conocimiento: Un análisis de la concepción del mundo de las clases subalternas
}

\section{Introducción}

Podría parecer paradójico a primera vista ir a la húscueda de la estructura básica de la sociología marxista en los escritos antisociológicos de Antonio Gramsci. Sin embargo, los comentaristas y analistas de su obra han puntualizado que su rechazo a la sociología positivista no significa un rechazo a la posibilidad de la existencia de la reflexión sociológica dentro de la tradición marxista. Loo que Gramsci critica es la función abstracta, conservadora e ideológica del positivismo; por lo tanto, la sociología, al mismo tiempo que liene que renunciar a sus ambiciones de elaborar un sistema absoluto de leyes sociales, puede contribuir a la comprensión de los orígenes, condiciones e importancia de los sistemas socioculturales. Cada sociedad posee su propio sistema de racionalidad. Lal sociología está llamada a descubrirlo, ideologizarlo y sustituirlo por un sistema de racionalidad que beneficie a la totalidad de la sociedad civil. Precisamente en esto consiste la relevancia actual del pensamiento de (iramsci en un período caracterizado por el abandono a la utilización de la teoría crílica del capitalismo y por una gradual adhesión a las diferentes "post-precocupaciones: post-industrialismo, postmodernismo, postcolonialismo" (Wallerstein 2()()()).

La presente discusión no intenla presentar un análisis exhauslivo del desarrollo de la sociología del conocimiento y exponer su relación con la epistemología 
marxista. Sin embargo, debido a que los análisis teóricos de Gramsci son aquellos que tradicionalmente se discuten en la sociología del conocimiento, la discusión se centrará en algunos problemas teóricos que han emergido en el proceso de su desarrollo, tal es la relación entre la filosofía y la sociología, la teoría y la ideología y el problema de la objetividad. Al mismo tiempo, se abordarán algunos aspectos de la realidad social marginalmente discutidos por la sociología positivista y que, por el contrario, se constituyen en elementos centrales en el pensamiento y en la reflexión sociológica de Gramsci: la concepción del mundo de las clases subalternas.

\section{Historicismo y la Sociología del Conocimiento}

El aspecto básico de la sociología del conocimiento, como lo han indicado Berger y Luckmann, es que la realidad social es construida, mantenida y distribuida socialmente en procesos "objetivos" permanentes; lo cual constituye el objetivo de la investigación empírica de la ciencia social. Sin embargo, la relación entre la sociología del conocimiento y la filosofía no ha sido uniformemente comprendido. Para Berger y Luckmann (1966), la filosofía se plantea interrogantes con respecto al estatus último de la "realidad", la sociología, por el contrario, al investigar las variaciones en los tipos de conocimiento está obligada a atribuirlo a la diferenciación estructural de las sociedades.

En la misma perspectiva, Gurvitch (1972) argumenta que la sociología del conocimiento nunca plantea el problema de la validez de las ideas, sino que intenta solamente establecer los efectos de su "presencia", su "combinación" y sus "funciones" efectivas. La filosofía, por otro lado, se preocupa por la justificación de la validez de las ideas. La sociología del conocimicnto, (iurvitch continúa, está limitada a la tarea de establecer las "correlaciones funcionales", las "tendencias regulares"y "la integración directa de las ideas en los esquemas sociales". En contraste, Mannheim (1952) tiende a identificar "conocimiento" con "ideología". Desde su punto de vista, la estructura social es el factor determinante que explica no solamente la diversidad sino también el contenido del pensamiento humano; consecuentemente, cada tipo de pensamiento es por naturaleza ideológico. Dicha identificación de conocimiento con ideología ha dado origen a cierto desencanto con la sociología del conocimiento en las décadas pasadas (Gurvitch 1972: 7-8). Como un intento de rescalar la sociología del conocimiento del impasse teórico producido por la identificación que Mannheim hace de conocimiento con ideología, Gurvitch ha insistido en la naluraleza empírica de la disciplina, cuyo objeto debe ser el análisis de los lipos de conocimiento: conocimiento perceptivo del mundo externo, conocimiento del Otro, conocimiento político, conocimiento técnico y conocimiento del sentido común. De igual manera, Stark (1958: 46-172) ha proporcionado una importanle distinción entre la sociología del conocimiento y la teoría del conocimiento (crítica ideológica) y la cual tiene una elaboración mas detallada en los trabajos de 
Gabel. Al respecto, Gabel (1979): 127-145) rechaza la creencia comunmente aceplada que Ideología y Utopia de Mannheim representa un texto de sociología del conocimiento y sostiene que es sobre todo un ejercicio de "crílica ideológica". La sociología del conocimiento sistemáticamente analiza los "lipos" de conocimiento e intenta establecer su origen social, no su determinación social. Al hablar del origen social del conocimiento es simplemente hacer referencia a una observación empírica; en contraste, la delerminación social del conocimiento implica adoplar una postura crítica con respecto a éste. Especílicamente, el origen social del conocimiento enfaliza la relación entre el conocimiento y la tolalidad de la estructura social - la que se presume homogéneal - sin ninguna consideración de la estructura de clases o del confliclo social; la determinación social del conocimiento hace énlasis en la relación del conocimiento con la estructura de clase, de modo que, en última instancia desalcredila sus pretensiones ideológicass y relaliviza la validez de su naluraleza cientílica y de su objetividad.

A pesar que Gramsci nunca no se definió como sociológo, sus preocupaciones lo llevaron a lomar posición con respecto a los problemas más tradicionales de la sociología del conocimiento, en parlicular el problema de la génesis de la Weltanschauunge'n o la consirucción intelectual de la realidad y su difusión en las clases sociales. (iramsci no elaboró una teoría sistemática del conocimiento; sin embargo, formuló algunos, y muy útiles, criterios hermenéuticos en torno al análisis sociohistórico.

Indudablemente, el enfoque que (iramsci utiliza para el estudio del conocimiento muestra prolundas similitudes con los escrilos del joven Marx, especialmente con La Ideología Alemana. En (iramsci lo mismo que en Marx. los hombres |y las mujeres| son los forjadores de la historia, no son espectadores de la historia, sujetos ciegos en relación al desarrollo de la tecnología, impotentes ante la presencia de las ideologías dominantes, desarmados ante el poder de las élites y los grandes tecoricos de los sistemas hurgueses. Por el contrario, la historia es la aclividad conciente de los seres humanos en la consecución de sus objelivos. La Ilistoria es, así, un ac/o político. En tal sentido, Ciramsci esti de acuerdo con la identilicación ideología-conocimiento propuesta por Mannheim, pero la ha llevado hasta sus límites al incluir el conocimiento cientílico. (iramsci rechaza cualquier intento de separar artilicialmente el problema de la determinación social del conocimiento con el problema de su origen social, como en las formulaciones de Stark y (iabel; al mismo liempo, alirma, en contraposición a Gurvitch y Scheler, la primacía del "conocimiento político" sobre cualquier otro tipo de conocimiento, incluyendo el conocimiento cientílico.

Gramsci ha ideologizado a la misma sociología y ha intentado claborar una sociología del conocimiento humanista e historicista, en la cual existe una subordinación completa de la totalidad de los fenómenos sociales a la conciencia 
crítica" de las masas. El conocimiento no es universal, y no puede ser absoluto en la medida que las estrucluras sociales se encuentren estratificadas. Gramsci parece proponet que la unificación estruclural de la sociedad es la precondición para la desideologización, despolitización y desalienación del pensamiento.

Gramsci acepta el principio enunciado por Marx y Engels de la determinación social del conocimiento, la afirmación que las ideas no tienen una existencia independiente, sino que siempre se concretizan en condiciones socio-económicas especificas y concretas, y que las ideas dominantes de un período histórico dado son siempre las ideas de las clases dirigentes. Pero puede un determinado tipo de conocimiento asegurar su objetividad? La respuesta de Marx es que siendo el conocimiento una función de los interses de clase, no existe la necesidad de demistificarlo o desalienarlo en una sociedad que ha alcanzado la condición de ser una sociedad sin clases. En otras palabras, la determinación social del conocimiento no es un obstáculo para el logro de la objetividad. Dicha posición ha sido criticada y rechazada por Mannheim, para el que todo conocimiento es parcial, relativo e ideológico por naturaleza. Si para Marx el factor social que condiciona el conocimiento puede determinar la deformación de la realidad solamente en condiciones históricas donde las clases proletarias no han logrado la hegemonía política ( $\mathrm{El}$ proletariado es el portador de la objetividad!), para Mannheim éste debe deformarla cualquiera que sean las condiciones. La tesis de Mannheim es mucho más radical que la de Marx en la medida que extiende el principio de la relatividad del conocimiento afectando al mismo marxismo. Gramsci trasciende a Marx y Mannheim. Como se ha indicado, Marx ha dejado de discutir en el problema de la determinación social del conocimiento y la consecuente deformación del pensamiento en las sociedades en las cuales el proletariado se ha convertido en hegemónico (Schaft, 1973). En el caso de Mannheim, la ideologización del pensamiento no es total. Las ciencias nalurales están exentas de las limitaciones de la determinación existencial. Para (iramsci, todo pensamiento es ideológico, incluyendo a la ciencia. "Sin el hombre, puede existir la realidad? Todas las ciencias están ligadas a las necesidades humanas y a la actividad del hombre" (Gramsci, 1966: 55). La realidad, de hecho, está siempre percibida y clasificada de acuerdo a las necesidades humanas.

Si la realidad como la concemos y si nuestro conocimiento cambia continuamente $\rightarrow$ i esto es asi, ninguna filosofia es definitiva, sino todas están históricamente determinadas- es difícil imaginar que la realidad cambie objetivamente con cambios en nosotros mismos. . . ¿ Qué son los fenómenos? Son algo objetivo, existen en y para ellos, o son (ualidades que el hombre ha aislado como consecuencia de sus intereses prácticos (la construcción de su vida cónómica) $y$ de sus intereses cientificos (la necesidad de descubrir un orden ('n el mundo) ydescribir y clasificar las cosas, como una necesidad que en si misma está conectada y mediada por intereses prácticos futuros)... El conocimiento es una superestructura (o una filosofía no definitiva). (Gramsci, 1971: 368). 
Si la ciencia no es un criterio para el conocimiento objetivo, existe algún otro criterio para respaldar la validez del pensamiento sin caer en un escepticismo o relativismo absoluto? Para Marx, en la sociedad sin clases el conocimiento será reunificado y la objelividad podrá lograrse; para Mannheim, un enfoque perspectivisla (una pluralidad de perspectivas) puede llevamos a la objetividad del pensamiento. Para Gramsci, la objetividad representa un consenso intersubjetivo entre los seres humanos; es decir, la objetividad es historiorizada y humanizada:

Objetivo siempre significa "humanamente objetivo" lo cual pucde sostenerse que corresponda exactamente a lo "históricamente subjetivo": en otras palabras, objetivo podria significar lo "universal subjetivo". El hombre conoce objetivamente en tanto el conocimiento es real para toda la raza humana históricamente unificada en un sistema cultural único... (Gramsci, 1971: 445).

Así, Marx, Mannheim y Gramsci están de acuerdo con la necesidad de idenlificar el conocimiento con la ideología. Lo que los separa, en mi opinión, es la noción de ideología. Para Marx la ideología denola un conjunto de ideas que reflejan la existencia social en una forma deformada, ilusoria y mistificada. En lanto Gramsci le asigna un valor y una connotación positiva. La ideología es una teoría que se encuentra en relación direcla con la praxis humana; de hecho, es a nivel de la ideología que los seres humanos se vuclven concientes del conflicto social. Consecuentemente, las ideologías tienen un valor histórico; representan una herramienta para la comprensión de los procesos sociohistóricos y una guía práctica para la realización de un determinado programa político. Iin este último sentido, las ideologías lienen también un valor psicológico; en electo, ellas son capaces de organizar a las masas. El análisis de las ideologías se convicrte para Gramsci en la base para la claboración de una teoría marxista del conocimiento. En tal sentido, las ideologías lienen en última instancia un valor gnoseológico, siendo la determinación de su valor histórico y psicológico el criterio para el establecimiento del pensamiento objetivo.

La metodología de la sociologia hurguesa (positivista) intenta describir, clasificar e interpretar los procesos socio-históricos de acuerdo a los criterios de validez. utilizados en las ciencias naturales. La aparente validez de dicha metodología presupone y es el resultado de la ausencia en las masas de una conciencia crítica y de su pasividad política. Además, para esta corriente la conciencia crítica es un obstáculo, micntras que la pasividad política es una condición favorable, para el avance del conocimiento científico. En contraste para (iramsci, la conciencia crítica y la voluntad humana organizada son los únicos elementos superestructurales capaces de impedir el desarrollo "objetivo" de la ciencia y la tecnología. Así, (iramsci en oposición al positivismo burgués y al marxismo "científico", minimiza hasta el punto de negar la dimensión objetiva de los pro-

Gromsci y lo sociologio del conocimiento: Un onálisis de la concepción del mundo 
cesos naturales y sociales; por el contrario, se enfoca en la dimensión subjetiva de dichos procesos. El factor subjetivo es de crucial importancia para la comprensión de los procesos históricos, así como también para la explicación de los procesos cognitivos. Pero, ¿cómo puede entenderse el papel que juega el factor subjetivo en el proceso cognitivo? Ciertamente, no en el sentido weberiano de la contribución individual en el proceso de conocimiento. Para Gramsci, la acción colectiva de las clases subalternas es la hase, y el criterio más importante, para la comprensión de la historia.

La sociología marxista del conocimiento es, entonces, una forma de conciencia crítica, una forma de pensamiento ideológico. Esto implica que la validez de la investigación sociológica no reside en su función científica sino en su función ideológica; es decir, en su capacidad de organizar las experiencias de las masas. En la medida que los sociológos faciliten el proceso de organización de dichas experiencias de una manera intelectual, su trabajo puede considerarse legítimo en el marco de una teoría crítica (marxista) de la sociedad. Su función se convicrte de una a-crítica, a-política, a-filosófica y supersticiosa "concepción de los mundos" que prevalece entre las clases subalternas, como lo son el "sentido común", el "folklore" y la "religión" a una concepción del mundo, históricamente más integral y universal, la cual es la "filosofía de la praxis".

La filosofía de la praxis no tiende a dejar al "sujeto" en su filosofia primitiva del sentido común, sino (juc los lleva a una concepción más alta de la vida... La conciencia de ser una parte particular de la fuerza hegemónica (esto es decir, la conciencia politica) es la primera etapa hacia una furura auto-conciencia progresista en la que la teoria y la práctica serán finalmente una... la auto-conciencia critica significa, histórica y políticams'nte', la creación de una élite de intelectuales... (Gramsci 1971: 332-334).

En esta perspectiva, el conflicto de clase se convierte para (iramsci en el conflicto visible de otro tipo de conflicto más profundo, el de la confrontación entre las contrucciones intelectuales de la realidad (Weltanschauungen). Lil proceso cognitivo se convierte así en una parte integral de los conflictos sociales y no puede ser analizado independientemente de su realidad.

En conclusión, la característica distintiva del enfoque marxista de (iramsci con relación a la teoría del conocimiento podría resumirse en los siguientes puntos:

- El historicismo es el componente esencial del marxismo. Consecuentemente, los problemas del historicismo son centrales en el desarrollo de la teoría del conocimiento.

- El historicismo es una perspectiva revolucionaria en la medida que sus funciones prácticas estén orientadas a la modificación de la existencia social y de las estructuras sociales existentes. 
- El marxismo es la “concepción del mundo" más integral, una fuerza histórica del desarrollo y del cambio. Al ofrecer a las masas una nueva visión del mundo, determina, como lo hace cualquier movimiento religioso, cambios prolundos en su forma de pensar y en su conducta.

- El desarrollo de las clases subalternas y su movimiento ascendente hacia una hegemonía cultural, ideológica y política es el criterio fundamental para el análisis de todos los fenómenos históricos, sociales y culturales.

- La dominación de una clase sobre la otra siempre es la dominación de una determinada Weltanschauung sobre otra; en consecuencia cualquier movimiento revolucionario, si inlenta ser líructílero, liene que ser precedido por una profunda relorma intelectual y moral, por una translormación radical de la conciencia. (La hegemonía es una relorma de la conciencia, señala (iramsci).

- La realización de la hegemonía política es el resultado de una relación dialéctica entre los intelectuales y las masas. Ll establecimiento de dicha relación trae consigo una transformación necesaria de las clases subalternas, así como una transformación radical del papel del intelectual, en la sociedad.

- El desarrollo político de las clases subalternas, en última instancia, es siempre una lorma de desarrollo cultural. Es decir, la actividad política liene como objetivo la creación de nuevas lormas culturales.

- La unificación cullural e ideológica de una sociedad es linalmente el resultado de su unilicación estruclural.

\section{El sentido común y el folklore: La concepción del mundo de las clases subalternas}

La sociología de (iramsci puede correclamente caracterizarse como la sociología política de la historia, una sociología que interprela la historia universal desde el punto de vista de la hisloria parlicular de las clases subalternas. Su sociología es historicista, macroscópica y dialéclica. Es una sociología cjue analiza el universo sociocultural desde una posición de tolalidad. $\mathrm{Al}$ igual que Lukács, Gramsci concibe dicha totalidad como el objelo determinante, así como el sujeto de conocimiento (Lukács 1972) precisamente es esla noción lo que separa la sociología marxista de la positivista. I a sociología positivista, en sus diferentes variantes, busca establecer las relaciones entre lenómenos y arribar a sus signilicados desde el contexio de lo inmedialamente dado y apararente del mundo de los hechos. En Gramsci, los hechos son solamente aspectos de un proceso histórico y dialéctico. El análisis de un lenómeno dado es incompleto si la historia de su desarrollo no es tomada en cuenta. Asimismo, la historia de un determinado fenómeno es también incompleto si no se consideran las interrelaciones entre los fenómenos. Es desde esta perspectiva general que Gramsci analiza varios problemas que se le plantean a la teoría y al cambio social. Los análisis de la

Gramsci y la sociologio del conocimiento: Un anólisis de la concepción del mundo 
enmacipación política y cultural de las clases subalternas, constiluye para (iramsci, uno de los problemas fundamentales de la leoría sociológica marxista.

La transformaeión cultural de las clases subalternas significa para (iramsci el paso de una condición de inmadurez cultural a una de autonomía cultural. La cultura popular tiene que ser transformada en una concepción de la realidad integral, y orgánica. Esto nos lleva a discutir el análisis sociológico que (iramsci realiza de la concepciones populares de la realidad y su lugar en la teoría marxista.

Los textos de Gramsci sobre cultura popular tienen sentido únicamente si son analizados en el contexto de su noción de "hegemonía". La pregunta básica que Gramsci lanza es la siguiente: ¿Cómo una clase social pasa de una posición subalterna a una hegemónica? Para Lenin la respuesta es obvia. Una vez que el poder es conquistado y la dictadura del proletariado es establecida le sigue una revolución cultural, una reforma intelectual y moral de las masas; es decir, una transformación en su conciencia. Para (iramsci, el proletariado debe convertirse en un grupo dirigente antes de la conquista del poder político. Lo que hace a un grupo social "dirigente” es la creación de una concepción del mundo.

La fundación de una clase dirigente (por ejemplo, de un Estado) es c'quiv'alente a la creación de una Weltanschauung. ¿Cómo debe entenderse la afirmación que el proletariado alemán es el heredero de la filosofia clásica alemana? Seguramente lo que Marx queria indicar era la función histórica de su filosofía cuando se convirtió én la la teoria de la clase que c'ventualmente se convirtiria en Estado (Ciramsci 1971: 381).

Si para Lenin el poder era la condición la para supremacía política y cultural de una clase, para Gramsci el problema es cómo un grupo social se convierte en grupo dirigente antes de lograr el poder y puede continuar siendolo despućs que la hegemonía política ha sido alcanzada (1971: 57-8). La hegemonía es "el liderazgo intelectual y moral" de las clases subalternas. Se realiza cuanclo una "reforma moral e intelectual" de la sociedad ha tenido lugar. La revolución no es un acto traumático, sino proceso orgánico y dialéclico que conlleva una transformación subjetiva en la conducta y en el pensamiento de las masas (Moulfe 1979: 168-204). Pero, ¿cuáles son las concepciones del mundo de las clases subaltemas y cuáles son sus principales características? La respuesta de Ciramsci es el sentido común y el folklore.

\section{$\rightarrow$ Sentido común}

La noción de sentido común en Gramsci es más sofisticada y compleja que las que se encuentran en la filosofía tradicional o en las sociologías fenomenológicas. El sentido común ha sido comprendido como "el senticlo general, sentimiento o juicio de la humanidad; con mayor precisión, como un conjunto 
de creencias que la mayoria de la gente siente que son verdaderas". Algunos autores han insistido en la espontancidad del sentido común y lo han definido como "la totalidad de las concepciones que son aceptadas en un periodo dado y en una comunidad especifica, espontáneamente y en tal cantidad que han sido consideradas como ordinariamente conocidas" (Grooten y Steenbergen 1972).

Dentro de los esquemas leóricos de las corrientes sociológicas de inspiración fenomenológica, en particular en la sociología de Schutz., Berger y Iuckmann, el sentido común ha sido entendido en oposición al pensamiento teórico como "Io que la gente "conoce" como "realidad" en su vida cotidiana" (Berger y Luckmann 1960: 14). En consecuencia, estas concepciones reviven el Ilamado sentido común realista típico de la escuela escoessa de libosolia, de acuerdo con la cual la teoría del conocimiento es elaborada desde una posición y en apoyo de las creencias realistas de la gente en la calle. Asi, el conocimiento de sentido común ha sido identificado ya séa teróricamente más adecuado (jue la libosolia, o en oposición a la "naluraleza crílica" de la liblosofía y de la metodologia cientifica pero finalmente reconcialiable con ellas, o definitivamente superior a todos los lipos de conocimiento dehido a su carácler masivo y universal (Berger y Luckmann).

El elemento común en todos estos enfogues lilosólicos y socioligicos del sentido común es la reducción de su contenido a una expresion de actilud natural, una concepción del mundo no racional o no cientílica, sino de ser prictica y universal. (iramsci rechaza dichos enlocpues al insistir en las caracteristicas hislóricas, ideológicas y políticas del sentido commin.

Gramsci señala en una formulación introductoria que el sentido común lue virtualmente exhaltado en los siglos diecisiete y dieciocho en el momento de una reacción intelectual a la libosolia aristotedica y a la autoridad de los principios hiblicos y Dios. La ciencia lo percibió como "una cierla medida de experimentacion" y de observación directa de la realidad a pesar de ser empirico y limitado (1971: 348). La lascinacion con el sentido común (pue expresa la sociología contemporánea es de alguna manera ideológica. lin oposición a los sistemas positivistas o pseudocientílicos, el sentido común es capary de identilicar las causals en forma transparente y producir juicios de una manera exacta, sencilla y príclica.

El sentido común, (iramsci indica, es una concepción del munclo mecrinicamente impuesta por una crialura extraña, por "uno de los muchos grupos socialles en los que todos están automálicamente involucrados desde el momento de su entrada en el mundo conciente” (1971: 32.3). El sentido común es un producto de la historia y debe ser analizado como "parte del proceso histórico". Para ser más explicitos, existen muchos sentidos comunes y no simplemente uno. Cada estrato social tiene su propio sentido común y cada corriente de pensalmiento deja atrás una sedimentación de sentido común que se cristaliza en un

Gromsci y la sociologio del conocimiento: Un anólisis de la concepción del mundo 
modo contradictorio en la conciencia popular. El poder de inlluencia que tiene la ideología dominante es visible en el contenido del sentido común. Por lo tanto, todos los enfoques filosóficos y sociológicos que delinen al sentido común de las clases subalternas como la base del pensamiento objelivo necesilan comprender la función ideológica que cumple el sentido común en las sociedades estratilicadas.

Para (iramsci, el sentido común es la filosofía de los no filosófos, la concepción del mundo típica de las clases subalternas en la fase negaliva de su desarroIlo; es decir, la fase de subordinación política y cultural con relación a los grupos dominantes y a sus ideologías. En contraste a la "filosofía", una concepción homogénea, coherente y sistemática del mundo, el sentido común representa una forma negativa, primitiva del orden intelectual.

El "sentido común" es el folklore de la filosofía, y está siempre a la mitad del camino entre el folklore propiamente hablando y la filosofia, la ciencia y la economía de los especialistas. El sentido común crea cl folklore del futuro; es decir, como una fase relativamente rigida del conocimiento popular en un lugar y tiempo dado (Cramsci: 1971: 326).

El sentido común existe en oposición a la filosofía y difiere cualitativamente de ella; sin embargo, es dependiente de la misma y funciona para integrar a los grupos subalternos a la cultura e ideología dominante. "Su característica fundamental es que se constituye en una concepción en la cual, incluso en el cerebro de un individuo, es fragmentaria, incoherente e inconsecuente, de conformidad con la posición cultural y social de aquellas masas cuya filosofía lo es" (Ciramsci, 1971: 419). El sentido común es cualitativamente inferior a la filosofía no solo por su manera incoherente y fragmentaria como se presenta, sino por su contenido, el cual es una acumulación de sedimentaciones de épocas pasadas, un "agregado caótico de diversals concepciones derivadas de varios grupos sociales. Por esta razón "se puede encontrar allí cualquier cosa que a uno le gusie"(1971: 422). De esta forma, concluye (iramsci, el sentido común es una "fase rígida del conocimiento popular" pero "continuamente transformándose y enriqueciéndose con ideas, opiniones derivadas de los sistemas metafísicos, principalmente de la religión".

Debido a la ausencia de una conciencia crílica, el senlido común es intrinsicamente incapaz de reflexionar histórica y dialécticamente. Su concepción de la realidad es, de hecho, estática, reificada, naturalista, fatalista y sus creencias son sostenidas por las masas como imperativos naturales. En este contexto, Gramsci rechaza tanto el enfoque psicológico de Sorel y el cientílico de De Man. En Sorel no hay una evaluación crítica del sentido común. Es importante aceptar y reverenciar los sentimientos populares, priorizar el sentido común, entenderlo y expresarlo en su forma racional y jurídica. El socialismo para Sorel es un sistema de justicia hasado en el sentido común. Para De Man, el 
famoso socialdemócrata helga, igualmente opuesto al marxismo, un retorno a "los valores psicológicos y éticos" de la clase obrera asegura la estrategia política apropiada. Su actitud hacia el sentido común es definido por (iramsci como "cientificista". De Man se inclina hacia el sentido común para "keorizar" sus sentimientos y construir esquemas pseudocientíficos de la misma manera que un zoólogo se siente orgulloso del mundo de los inseclos. "Su posición es la de un estudiante académico del folklore que es permanentemente temeroso de yue la modernidad vaya a destruir el objelo de su estudio. De Man estudia Ios sentimientos populares, pero "no los siente para guiarlos, y los lleva en una calarsis de la civilización moderna” (Gramsci 1971: 419).

Contra Sorel y De Man, y ciertamente contra todas las sociologías del sentido común, Gramsci propone una interpretación política del sentido común. Es suficiente mencionar que el carácter fragmentario, incoherente, antropomórlico del sentido común es la mejor documentación de su subordinación política e intelectual y de la naturaleza "primitiva" de su contenido. (iramsci intenta probar que la inmadurez politica y cultural de las clases subalternas es la base de la hegemonía política y cultural ejercida por otras clases. Por esta razón su análisis del sentido común sirve para demostrar por qué las clases populares han fracasado en su intento de lograr la hegemonía política a través de la historia. Al analizar los mecanismos mediante los cuales los grupos dominantes se manticnen en el poder, (iramsci hace énfasis en la función de los sistemas filosóficos tradicionales.

Estos sistemas influyen las masas populares como una fiucra politica externa, un elemento de fuerza cohessiva ejercida por las clase's dirige'nle's y por lo tanto un eleme'nto de subordinacion a una hegemonia cxterna. Eiste limila el pensamiento original de las masas populare's e'n una dirección negativa, sin tener un efecto positivo de un fermento vital de Iran.sformación interior de lo que las masas piensan en una forma caótica y embriónica aceréa del mundo y la vida (1971: 42())

La historia de la filosofia. . es la historia de intentos que se han herho y de las iniciativas ideológicas retomadas por clases especificas de gente para cambiar, corregir o perfeccionar las concepcione's del mundo gue existen e'n una época particular y asi cambiar las normas de conducla que l'a con ellas; en otras palahras, cambiar la actividad práctica como un lodo (1971: 344).

Pero si el sentido común es esencialmente un agregado caótico de concepciones heterogéneas del mundo sedimentadas en la conciencia de las masas populares, esto no significa que tiene que ser desechado como una fuente de conocimiento y de acción política. Gramsci hace notar que al interior del sentido común existe un núcleo positivo, un elemento creativo, el cual si es desarrollado puede llevar a la elaboración de una conciencia autónoma y a un sentido común

Gramscl y la soclologio del conocimiento: Un anólisis de la concepción del mundo 
renovado. Este es un sentido correcto, el embrión de un pensamiento crítico (1971: 328). El sentido común purgado de sus elementos a-críticos puede convertirse en la base de una nueva concepción del mundo de las clases populares. La consirucción de la lilosolía de la praxis, como la concepción del mundo de las clases subalternas, descansa en una crílica y en una trascendencia del sentido comin.

\section{Folklore}

Como en el caso del sentido común, los análisis de (iramsci sobre el folklore responden a dos exigencias. Por un lado, intentan mostrar los procesos por medio de los cuales las clases dominantes ejercitan su control cultural y político. Por el otro, huscan al interior de la cultura popular un saludable núcleo de ideas y experiencias, las cuales educadas, podrían convertirse en una concepción superior del mundo, capaz de superar los sistemas filosóficos más refinados y claborados que prevalecen en la sociedad. La caracterización negativa del sentido comun y del folklore responde a la necesidad de crear una nueva cultura de masas.

El folklore es la lorma más inlerior de la cultura y del pensamiento lilosólico lambién lípico de las clases subalternas que viven en la periferia de las hegemonías dominantes. Fis un producto derivado de la "alta" cultura de las clases dominantes y su función es la de mantener la cultura popular en una posición subordinada. Al mismo liempo, el folklore es la concepción que asegura el mantenimiento de la unidad ideológica al interior de un bloque social (1971: 328). En los estudios convencionales sobre el folklore, éste es concebido como un objeto de erudición, un pasatiempo intelectual, como algo trivial, extraño o pintoresco. Para (iramsci, el lolklore es por el contrario un dispositivo que contribuye a la comprensión histórica de una Weltanschauung global que prevalece en un período histórico determinado. De igual manera, Gramsci lo considera como una concepción del mundo ligada y subordinada a la cultura dominante y a las hegemonías intelectuales caracteristíca de ciertos estratos populares. El folkore, señala, es "el sistema completo de creencias, supersticiones, opiniones, modos de percibir las cosas y de formas de acluación" (1971: 32.3). Tres ideas parecen subrayar la concepción gramsciana del folklore. Primero, es una "coneepción del mundo" que contiene un corpus específico de creencias, normas y valores. Como tal, es la rellexión de las condiciones de primitividad cultural de las clases populares. Segundo, se mantiene en oposición a la concepción oficial de las clases dominantes. Tercero, es la característica de aquellas clases que son excluidas de la participación en la hegemonía cultural de la nación, principalmente el campesinado. Gramsci procede a realizar dos series de observaciones sobre la anturaleza y organización social del folklore. 
Como en el caso del sentido común, características negativas caracterizan el fenómeno del folklore. Es una "conglomeración desorganizada de fragmentos de todos los puntos de vista sobre el mundo desarrollados a lo largo de la historia, la mayoría de los cuales se encuentran en el folklore como documentos que sobreviven mutilados y contaminados" (Davidson 1969: 27). El carácter no claborado y a-sistemático del folklore tiene su hase en la propia naturalezal de las clases subalternas, las cuales por definición son incapaces de desarrollar puntos de vista elaborados, sistemáticos, políticamente centralizados y organizados (Davidson 1969: 28). Con esta idea, lo que (iramsci quiere dar a entencler es que el alto grado de sistematización y claboración de las concepciones del mundo son consecuencia y expresión de una hegemonía malenida en lodo el organismo social. Por el contrario, la Weltanschauung popular a-sistemática y no elahorada es el resultado de la falla de una participación hegemónica. Nada resulla más contradictorio y fragmentario que el folklore, escribe (iramsci. Diversos elementos de sistemas de pensamiento opuestos se han congelado en la conciencia popular. Existen como valores fosilizados.

Dentro del folklore se encuentra una "moralidad popular", que ensambla las máximas de la conducta práctical derivadas de la creencias y supersticiones. I a ciencia moderna también introduce nuevos elementos en el folklore moderno. De hecho, "ciertas ideas científicas y opiniones, divorciadlas de su contexto global y más o menos desfiguradas, continuamente caen en el conocimiento popular y son 'insertadas' en el mosalico de la Iradición” (Davidson 1969): 27).

El problema de la naturaleza del folklore más que su organización social es lo que principalmente parece interesarle a (iramsci. Iin lal sentido, lo examina como un fenómeno dependiente de las ideologías dominantes, asi: "el lolklore siempre ha estado atado a la cultura de la clase dominante, y, a su propia manera, se ha apropiado de ciertos aspectos de éstia, lo cual se hal convertido en parte de las Iradiciones precedentes" (Davidson 1969: 9). I a mayoría de los elementos esenciales del folklore son conservaclores. Fistos son reteniclos por la gentes como ideas objetivadas, cosilicaldas y que sirven para perpeluar una estralificación cultural en la sociedad. De nuevo, como en el caso del sentido común, Gramsci no rechaza el folklore en su lotaliclad. Individualiza dentro de éste un "núcleo saludable" de elementos positivos y progresistas los cuales, si son replanteados, pueden ser incorporados en una concepcicin del mundo más elevada, la filosofia de la praxis. Existen "algunos imperallivos" mais tenaces y efectivos que la moralidad oficial, una "seric de innovaciones a menudo creativals y progresistas, determinadas espontíncamente por nuevas formas y condiciones de vida opuestas o diferentes a la moral de las clases dirigentes (Davidson 1960): 27). Las masals poseen, sin embargo, crilerios de evaluacion sencillos y originales. Gramsci cita el caso de las canciones populares que no son escritas por las clases populares ni orientadlas hacia su audencia, pero "adoptadas por ellas porque se ajustan a su modo de pensar y a sus sentimientos" (Davidson l(96): 21 ).

\section{3}

Gromsci y lo sociologio del conocimiento: Un onálisis de lo concepción del mundo 
Lo que distingue una canción popular en el contexto de un país y de su cultura no es la calidad artística, ni el origen histórico, sino la manera como ésta peŕcibe el mundo y la vida, en constraste con la percepción oficial. En esto podemos huscar la "colectividad" de la canción popular y de lo popular en si mismo (Davidson 1969: 27).

Dichos elementos críticos y progresistas son fuerzas potenciales de cambio. La filosofía de la praxis está llamada a transformar la concepción folklórica del mundo de la cual son portadoras las clases populares, al incorporar y desarrollar posteriormente su "núcleo positivo". La creación de una cultura nueva trae consigo una catarsis del folklore". El cual tiene que despojarse a si mismo de sus elementos particularísticos y localistas y convertirse en un verdadero fenómeno nacional-popular. El pensamiento folklórico, Gramsci indica, es un modo provincial de pensamiento, en el sentido de ser anacronístico y típico de una clase que se caracteriza por ser no tener un carácter universal. Y se constituye en "nacional-popular" cuando logra un nivel de cultura universal y cosmopolita.

\section{Consideraciones finales}

Los criterios metodológicos de la sociología de Gramsci son los mismos utilizados por la concepción materialista de la historia, por el marxismo hisıórico. Desde esta perspectiva, la sociología no solamente estudia la relación de las parles de una estruclura social determinada, sino también la interrelación entre el todo y las partes. El todo puede determinar la estructura cualitativa de las partes y las partes pueden determinar la estructura cualitativa del todo. La sociología de Gramsci parece ser un intento teórico de analizar la estructura dinámica de la sociedad desde una posición de su desarrollo global y del desarrollo de sus partes. A diferencia de la sociología hurguesa, la sociología crítica materialista entiende la historia y la sociedad como praxis política, como un proceso de subjetivización de la dimensión objetiva de la realidad.

Como "sociólogo del conocimiento", Gramsci ha insistido en la necesidad de analizar el contexto social de las ideas. En su esquema básico, la ideologización del pensamiento es llevada a una posición límite; la teoría del conocimiento se convierte en una teoría de la ideología; la totalidad de los fenómenos socioculturales se encuentra finalmente subordinada al criterio hermenćutico de la "conciencia crítica" de las clases subalternas, la cual es desarrollada en el momento ascendente hacia una hegemonía política e ideológica. Para Gramsci, la sociología del conocimiento se transforma en una forma de conciencia crítica. Su validez reside en su función ideológica de organizar intelectualmente la experiencia de las clases subalternas.

En la misma línea de pensamiento, la sociología Gramsci no se limita a comprender el sentido común, sino transformarlo. Su análisis del sentido común es eminentemente político, en la medida en que sus reflexiones se enfocan en las 
contradicciones básicas y objetivas, masas y élites, masas e intelectuales, clases dominantes y clases subalternas, tcoría y praxis. La filosofía de la praxis en Gramsci es simplemente un sentido común renovado, la concepción del mundo de las clases subaltemas que aspiran a lograr una hegemonía política y cultural.

La dominación de una clase sobre otra es siempre la dominación de una determinada Weltanschauung sobre otra; consecuentemente, cualquier movimiento revolucionario, si quiere serlo realmente, tiene que ser precedido por una profunda reforma intelectual y moral, por una transformación radical de la conciencia de las gentes. La hegemonía es una reforma de la conciencia de los agentes sociales. Por lo tanto, la reforma social se constituye para (iramsci en el proceso de emancipación política, moral y cultural de las clases subalternas.

Bini.iogiralia

Berger, P. y T. Luckmann (1966) The Social Construction of Reality: a Treatise of Sociology of Knowledge. Garden City, New York: Doubleday.

Davidson, A. (1969) Antonio (iramsci: The Man, His Ideas. Sidncy: Australian Left Review.

(jabel , J. (1969) "Mannheim el le marxisme hongrois" en I. 'Homme el la Socicle 11. 127-4.5.

Gramsci, A. (1971) Selection from the Prison Notebooks. Ouintin Hoare and (ieoffrey Nowell (eds. y trans). Nueva York: International Publishers. (1966) Il Materialismo storico a la filosofia di Benedento C roce.

Torino: Einaudi.

Grooten, J. y (B.Steen (1972) New Iincyclopedia of I'hilosophy.

Gurvitch, (j. (1972) The Social Frameworks of Knowledge. Nueva York: Harper and Row.

Lukacs, (3. (1972) Hisıry and Class Consciousness. Cambridge. Mass.: MIT' Press.

Mannheim, K (1952) Essays on Ihe Sociology of Knowledge. I .ondres: Routledge and Kegan Paul.

World, Inc.

Mouffe, Ch. (1979) "Hegemony and Ideology in (iramsci" en (h. Moulle (ed.) Gramsci and Marxist Theory. I ondres: Routledge and Kegan Paul. 168-204.

Schaft, A. (1973) Language and (ognition. Nueval York: Mc(iraw Hill.

Slark, W. (1958) The Sociology of Knowledge. Chicago: (ilencoe, Free Press.

Wallerstein, I. (20(0)() "From sociology to historical science: prospects and obstacles" en British .lournal of Sociology Vol. I No. 51 lssue No. I (enero/ marzo 20(0)). 25-35.

Gromsci y la sociologio del conocimiento: Un onólisis de la concepción del mundo 